\title{
A LAS PALABRAS YA NO SE LAS LLEVA \\ EL VIENTO: APUNTES PARA UNA HISTORIA CULTURAL DEL FONÓGRAFO EN MÉXICO \\ $(1876-1924)^{1}$
}

\author{
Jaddiel Díaz Frene \\ El Colegio de México
}

$\mathrm{Z}^{\mathrm{n} \text { el presente trabajo indagaremos sobre los usos socia- }}$ les y expectativas generadas en la vida cotidiana mexicana por uno de esos milagros de la modernidad finisecular: el fonógrafo. La máquina del sonido, creada por Thomas Alva Edison en la década de 1870 y perfeccionada en los años posteriores, fue una pieza imprescindible en el inventario cultural de una época, cuyas matrices comunicativas se transformaron con el funcionamiento extensivo de la radio durante la década de 1920.

Durante este periodo, la utilidad del novedoso invento no se limitó a fines musicales, sino que inundó todos los ámbitos de la vida nacional. En 1890, México se convirtió en la

Fecha de recepción: 8 de julio de 2014

Fecha de aceptación: 4 de agosto de 2015

1 Agradezco los comentarios y sugerencias de Guillermo Zermeño, Engracia Loyo, Pilar Gonzalbo, Yvette Jiménez de Báez, Viviana Bravo y John Koegel. Cristóbal Díaz Ayala, siempre atento, me ofreció las primeras pistas sobre archivos con grabaciones mexicanas. 
primera nación en firmar un contrato para utilizar los fonógrafos en el servicio postal. ${ }^{2}$ El gobierno mexicano había observado en el nuevo invento una ventaja para que los miles de ciudadanos analfabetos pudieran grabar sus mensajes sin necesidad de acudir a la escritura. No era extraño entonces que los amantes porfirianos pensaran enviar sus declaraciones pasionales en discos, llevando a cabo "nuevas operaciones sensoriales” que afectaban lo que Niklas Luhmann llama "semántica del amor". ${ }^{3}$ Al mismo tiempo, los juristas planteaban su utilización en los tribunales, mientras las niñas de fin de siglo pedían a las hadas europeas o a las vírgenes mexicanas la posibilidad de estrechar una muñeca fonográfica.

Por estos años, los fonógrafos también alteraron las formas de circulación y socialización de la cultura política. Los discos con las palabras de Porfirio Díaz, los corridos de la Revolución y las narraciones actuadas de la intervención francesa, llegaron a los oídos de miles de obreros y campesinos que jamás pisaron una escuela ni podían descodificar la escritura. Estos discursos sonoros muestran otras prácticas, formatos y espacios para entender la construcción de la memoria popular de sucesos importantes del calendario nacional.

Lejos de ser visto como un instrumento curioso de la vida elitista, el fonógrafo aquí es una puerta de entrada para pensar, desde otras claves, una historia social de la comunicación en México. Asuntos centrales de la vida política

${ }^{2}$ Véase Periódico Oficial del Estado Libre. Y soberano de Campeche, Campeche (viernes 3 ene. 1890), p. 3. Más adelante hago referencia al artículo.

${ }^{3}$ Luhmann, El amor como pasión, p. 9. 
y cultural del país, como las estrategias estatales sobre la explotación de los medios de comunicación, las mediaciones de las empresas estadounidenses en la construcción de la cultura política, así como los usos populares de las tecnologías de la información, son revelados al explorar los procesos de producción, circulación y consumo del asombroso artefacto.

Sin embargo, a pesar de su impacto en la vida cotidiana, sorprende la escasa atención prestada al aparato en los manuales de comunicación y las investigaciones latinoamericanos, en comparación con el interés mostrado hacia otros medios como el cine, la televisión y la radio. ${ }^{4}$ Entre quienes lo han tenido como foco de su preocupación teórica puede señalarse a Marshall McLuhan. En un breve ensayo titulado "El fonógrafo. El juguete que encogió el pecho nacional", el pensador canadiense señala dos cuestiones que retomamos en este trabajo. La primera es la recuperación, protagonizada por el fonógrafo, junto con el telégrafo y el teléfono, del "mundo vocal, auditivo y mimético, oprimido por la palabra impresa" durante varias centurias de dominio gutenbergiano. ${ }^{5}$ Otra cuestión señalada por McLuhan es lo que él llama el aporte de un repertorio musical internacional de tres siglos "en el que la canción popular china era tan accesible como la húngara”. ${ }^{6}$ En el caso mexicano el amplio muestrario musical fonográfico no sólo permitió la importación de ritmos foráneos como el danzón, ampliamente adaptado

\footnotetext{
${ }^{4}$ No obstante, habría que señalar que en el ámbito estadounidense y europeo han proliferado los estudios sobre la industria fonográfica, así como el rescate de la música atesorada en los discos.

${ }^{5}$ McLuhan, Comprender los medios de comunicación, p. 321.

${ }^{6}$ McLuhan, Comprender los medios de comunicación, p. 325.
} 
a la vida cotidiana nacional, sino también la consagración y legitimación de nuevos géneros manados de la cultura política popular, como el corrido. ${ }^{7}$

La grabación de diferentes géneros musicales también incidió en la circulación cultural entre grupos sociales diversos. Mientras muchos campesinos, imposibilitados de pagar las entradas a los grandes teatros, tuvieron acceso a las óperas sin la necesidad de presenciar la interpretación, ${ }^{8}$ los sectores cultos pudieron degustar las composiciones típicas de la cultura popular, aunque también rescatarlas con fines antropológicos y utilizarlas como estrategia nacionalista.

Además de sobrepasar las fronteras sociales, los fonógrafos aliviaron las nostalgias de los migrantes, ya que pudieron viajar con los sonidos de sus pueblos y naciones en el equipaje o adquirir esos discos en el país receptor. Como dato relevante podemos señalar que la empresa estadounidense Victor, consciente del gran mercado interno de inmigrantes, había lanzado para 1920, de acuerdo con datos ofrecidos por el musicólogo cubano Cristóbal Díaz Ayala, "cerca de 6,000 números étnicos, ofreciendo grabaciones en lituano, ucraniano, holandés, serbio, croata, yidish, rumano, eslovaco,

7 Varias agrupaciones cubanas grabaron discos con danzones entre 1910 y 1917, los cuales llegaron seguramente al público mexicano. En este sentido sobresalen la orquesta del Teatro Alhambra, dirigida por Jorge Anckermann, la orquesta de Domingo Corbacho, la de Félix González y la de Enrique Peña. Entre estas figuras sobresale el músico Babuco, de nombre Tiburcio Hernández, quien además de grabar danzones en México en 1910, fue llevado a la capital mexicana una década más tarde para tocar en el Salón México, conocido como "el santuario del danzón mexicano”. Véase Díaz, Cuba canta y baila, consultado en http://latinpop.fiu. edu/discography.html

${ }^{8}$ Gitelman, "Reading Music”, p. 265. 
finlandés y otros idiomas". ${ }^{9}$ Para el interés de este trabajo, el fenómeno migratorio con Estados Unidos posee características insoslayables. Los discos con la música mexicana, interpretada por artistas nacionales y grabada por compañías estadounidenses, permitieron a los migrantes disfrutar de su "cultura de origen" y recrearla en actividades colectivas y privadas. ${ }^{10}$ Debe tenerse en cuenta que estas grabaciones también fueron consumidas a lo largo y ancho del territorio mexicano. Por su parte, el tránsito fronterizo no se limitó a los discos, según puede observarse en los partes aduanales; los migrantes aprovecharon también para ingresar al país algunos fonógrafos que podían traer como regalo a sus familiares o para acompañar sus estancias definitorias o vacacionales.

El estudio de estos procesos de comunicación coloca sobre la mesa de debate un asunto ineludible para los teóricos de la cultura: la lucha entre la dominación de la máquina, y tras de ella las élites, y la resistencia del consumidor, el cual no siempre debía ser popular. $\mathrm{Al}$ abordar la puesta en práctica de este nuevo "contrato comunicativo", la historiografía parece dividirse entre los estudios que privilegian el análisis de las características tecnológicas del artefacto, los anuncios publicitarios y la divulgación musical, y aquellos que ponen énfasis en la reconstrucción de las prácticas de los consumidores, ámbito en el que destaca el artículo de Lizabeth Cohen titulado "Encountering Mass Culture at

${ }_{9}$ Díaz Ayala, Cuba canta y baila, consultado en http://latinpop.fiu. edu/discography.html

${ }^{10}$ Del mismo modo, las grabaciones con música estadounidense les posibilitaron aprender el inventario musical del país receptor para adaptarse a sus códigos culturales y mejorar sus habilidades lingüísticas. 
the Grassroots: The Experience of Chicago Workers in the 1920s", ${ }^{11}$ sobre el cual volveremos más adelante. ${ }^{12}$

En el presente trabajo, si bien se integran algunas preocupaciones metodológicas de ambas líneas historiográficas, no se agotan los múltiples temas y problemas teóricos que pueden desprenderse del análisis del invento decimonónico. Mi propósito, además de llamar la atención de los historiadores sobre un tema poco trabajado en México, se limita a responder tres preguntas que dan cuenta de la influencia de la "máquina del sonido" en la sociedad mexicana, a partir de los intereses y las experiencias de diferentes grupos sociales: ¿cuáles fueron las opiniones, propuestas y debates que se expresaron en torno a la utilidad de la "máquina parlante” en las páginas de la prensa nacional? ¿Mediante cuáles estrategias sectores sin un elevado nivel adquisitivo pudieron acceder al consumo de estos aparatos? ¿Es posible encontrar fuentes que permitan reconstruir estas experiencias? Expedientes judiciales, discos fonográficos, artículos periodísticos y testimonios impresos y orales posibilitan llevar a cabo este primer acercamiento, que forma parte de una travesía académica mayor.

EL CORREO, LA JUGUETERÍA Y LA SORDERA. DIFERENTES

DEBATES DESDE LA PRENSA MEXICANA SOBRE LA UTILIDAD DEL FONÓGRAFO

El 5 de mayo de 1878, poco tiempo después de la invención del fonógrafo, el periódico capitalino El Combate

${ }^{11}$ Cohen, "Encountering”, pp. 8-9.

${ }^{12}$ Véase Thompson, "Machines, Music, and the Quest for Fidelity”, p. 134. 
reprodujo un artículo publicado en la prensa madrileña en el que, al mismo tiempo que se calificaba al artefacto como "uno de los prodigios más inverosímiles del cerebro humano", se alertaba al público mexicano sobre sus aplicaciones cotidianas. A partir de ese momento, señalaba el rotativo, se convertiría en una mentira el antiguo axioma: "a las palabras se las lleva el viento". Además, el fonógrafo y su capacidad de grabar y preservar las conversaciones ponía contra la pared a políticos y amantes mentirosos. De aquí que la ciencia se ponía al servicio de los más débiles en las relaciones de clase y las diferencias de género. A las jóvenes "crédulas y sensibles" se les daba el siguiente consejo: "armaos cautelosamente de un fonógrafo y cuando el falso os jure amor eterno y os ofrezca su vida, su alma etc., depositad sus falaces juramentos en el precioso aparato, para cuando llegue la ocasión". ${ }^{13}$ Asimismo, el articulista "a favor de las damas" se preguntaba sobre la posibilidad de convertir la pesada máquina al tamaño y forma de un abanico, con el propósito de cumplir mejor su función encubierta. ${ }^{14}$

El interés por la utilidad del fonógrafo manifestado en este artículo no representaba una actitud aislada. Desde la década de 1870, los rotativos internacionales comenzaron a publicitar el nacimiento del nuevo artefacto y sus múltiples aplicaciones en la vida cotidiana. La prensa porfiriana no fue la excepción. Sus páginas, además de reproducir cables extranjeros y artículos especializados sobre el tema, también

\footnotetext{
13 El Combate, México (5 mayo 1878), p. 1.

${ }^{14}$ Sobre la aplicación del fonógrafo en el trabajo de la imprenta véase "El fonógrafo en la tipografía”, en La Convención Radical Obrera, órgano de la sociedad del mismo nombre y de las clases obreras de toda la república, ciudad de México, 9 de septiembre de 1894 [ p. 3, ], cols. 2-3.
} 
divulgaron los debates internos acerca de las implicaciones fonográficas en el progreso nacional.

En un artículo titulado "El nuevo fonógrafo Edison", publicado en el México Gráfico en 1890, se hacía referencia al uso del fonógrafo en el mundo epistolar vinculado a la efectividad de la pequeña empresa. El escrito señalaba lo siguiente:

Supóngase que un comerciante desea escribir una carta. Se acercará á la embocadura de su fonógrafo, y poniendo el motor en movimiento por un sencillo contacto, pronunciará lo que desee con el ordinario timbre de voz. Una vez listo retirará la palanca de metal que habrá quedado impura, pudiéndola remitir por correo al interesado.

El destinatario, al recibirla, la colocará en su fonógrafo, y moviendo el motor, el mismo instrumento hará la lectura del contenido con el tono empleado por el dictador y más claro y característico que lo de un teléfono de los usados hasta ahora. ${ }^{15}$

El ejemplo del comerciante como consumidor poseía una doble funcionalidad: al mismo tiempo que señalaba a un comprador potencial del producto, dados sus altos precios en esta primera etapa, indicaba la utilidad de la máquina en el sector económico. Asimismo, la palabra grabada en su estado natural, sin la necesidad de reproducirla en códigos gráficos, ofrecía rapidez y menos intermediarios - es decir, alguien que escribiera o mecanografiara - en el proceso de emisión y recepción del mensaje. La intensidad del sonido reproducido por el fonógrafo, "dos veces más potente que lo que dará ningún teléfono”, catalizaba la claridad del

${ }^{15}$ México Gráfico, México (18 abr. 1890), p. 7. 
mensaje, así como su carácter privado, pues, como señalaba el articulista, "no ha de convenir al comerciante que oiga el contenido de la carta el personal todo del escritorio". ${ }^{16}$

No era ésta una visión aislada dentro de las aplicaciones, presentes y futuras, atribuidas al artefacto. Precisamente, el 8 de marzo de 1890, Manuel Romero Rubio, secretario de Estado del gobierno porfiriano, y Manuel Peniche, representante de Thomas Alva Edison, se reunieron para modificar un primer convenio del 8 de noviembre del año anterior, en el cual se había acordado utilizar los fonógrafos en el servicio de correos mexicano. El acuerdo creó tanta conmoción que llegó a celebrarse una conferencia en el Teatro Principal de la capital, donde Ramiro Ortiz, uno de los directivos más respetados del servicio postal mexicano, leyó las consideraciones de un profesor de la escuela de ingeniería de la ciudad. El texto, además de señalar a los científicos de la época “encerrados en sus laboratorios” como "los verdaderos revolucionarios”, resaltaba también el impacto de la fotografía, el teléfono y el fonógrafo en la transformación “del registro del lenguaje y la escritura". ${ }^{17}$

Para la fecha, la prensa de otros estados ya se había hecho eco de la noticia que convertía a México en la primera nación dispuesta a llevar a cabo semejante salto en el sistema de comunicaciones. El periódico oficial del gobierno de Campeche publicó, el viernes 3 de enero, los detalles del primer contrato. El artículo, firmado por el Partido Liberal, mostraba - tras las múltiples ventajas del aparato en el servicio postal mexicano - la postura de un gobierno de vanguardia ante

${ }_{16}$ México Gráfico, México (18 abr. 1890), p. 7.

${ }_{17}$ Milhe, Una visión de 1890, pp. 23-24. 
las innovaciones de la ciencia. Se señalaba, en este sentido, la atinada actuación del señor Romero Rubio, así como el papel pionero desempeñado por la nación mexicana en la introducción del fonógrafo en el sector de las comunicaciones. ${ }^{18}$

Pero concretamente, ¿qué ventajas propiciaría el fonógrafo en el servicio de correos mexicano? En primer lugar, según argumentaba la crónica, este medio permitiría oúr la voz de los familiares y reproducirla cuantas veces el destinatario lo considerara necesario. Y mejor aún, la ausencia de escritura, así como el bajo precio del servicio, permitiría el acceso a los sectores iletrados. El servicio postal fonográfico también aseguraría la privacidad de las cartas, teniendo en cuenta que las firmas eran más fáciles de falsificar que la voz. En el contrato convenido con Edison los gastos para México serían mínimos ya que "el servicio de los fonógrafos, así como su instalación, conservación y reparación corren por cuenta de la empresa". ${ }^{19}$

Vale destacar, respecto a las cláusulas referidas a las ganancias, que realmente el contrato no parecía "tan ventajoso para el público y el Gobierno" como aseguraba el texto. ${ }^{20}$ Por una parte, es cierto que el Estado mexicano podía rescindir el contrato en los próximos seis meses, sin que la empresa estadounidense tuviera derecho a exigir indemnización, así como

${ }^{18}$ Según el artículo, México era "la primera nación” que introducía "en su servicio postal esa mejora", dato que habría que corroborar. Véase Periódico Oficial del Estado Libre y Soberano de Campeche, Campeche (viernes 3 ene. 1890), p. 3.

19 Periódico Oficial del Estado Libre y Soberano de Campeche, Campeche (viernes 3 ene. 1890), p. 3.

${ }^{20}$ El convenio quedó sin efecto debido a la aparición del teléfono, que logró la comunicación oral a larga distancia. Véase Milhe, Una visión de 1890 , p. 25. 
permitir a las "autoridades superiores" hacer uso del invento en actividades oficiales. Sin embargo, por la otra, quedaba señalado que $90 \%$ de las ganancias generadas en el servicio postal engrosarían las arcas "edisonianas", además de cuatro pesos mensuales por cada artefacto. El convenio era explicado de esta forma: "Del producto bruto de cada fonógrafo se separarán mensualmente cuatro pesos para la empresa, y del resto, que se considerará como producto líquido, se entregará al Gobierno el diez por ciento, quedando el noventa por ciento restante en favor de la misma Empresa". ${ }^{21}$

Lo cierto es que desde años atrás las aplicaciones del fonógrafo en México habían llamado la atención de Porfirio Díaz, quien quiso tomar cartas en el asunto legislando en favor de Thomas Alva Edison, el 29 de septiembre de 1888. Apoyándose en lo convenido en la ley del 7 de mayo de 1832 y en su reglamento de 12 de julio de 1852, el presidente concedió diez años de privilegio exclusivo al inventor estadounidense. 150 pesos era el monto que debían pagar "los interesados" por derechos de patente. ${ }^{22}$

A pesar de la investidura presidencial, no puede separarse a Porfirio Díaz de las reacciones de asombro y esperanza ocasionadas por el fonógrafo en el cambio de siglo. Tampoco puede olvidarse que el reconocimiento y la aplicación pionera del artefacto reforzaban la imagen progresista que abanderaba su gobierno. Ambos aspectos, la fascinación ante la tecnología y la audacia política, pueden desprenderse de su conducta, cuando en 1890 , durante las negociaciones

${ }^{21}$ Periódico Oficial del Estado Libre y Soberano de Campeche, Campeche (viernes 3 ene. 1890), p. 3.

${ }_{22}$ Periódico Oficial del Gobierno del Estado de Hidalgo, Hidalgo (11 abr. 1889), pp. 12-13. 
acerca de la aplicación de los fonógrafos en el servicio postal mexicano, envió en un cilindro palabras de agradecimiento a Edison por su invención. ${ }^{23}$

La relación entre Porfirio Díaz y Thomas Edison continuaría en las siguientes décadas. En 1894, Edison obsequió al presidente como regalo de cumpleaños "una lujosa máquina de cilindros así como una gran cantidad de las primeras copias cilíndricas de música mexicana”, hechas meses antes en la ciudad de México. ${ }^{24}$ Díaz, por su parte, agradeció al inventor estadounidense en una misiva graba$\mathrm{da}$ "en un cilindro maestro de cera" con fecha 15 de agosto de 1909, en respuesta a una carta enviada por Edison el 8 de julio de ese año. En el mensaje fonográfico, "reproducido y vendido al público de México y Estados Unidos", 25 el caudillo oaxaqueño no sólo se refería a Edison como "estimado y buen amigo", sino que también lo colmaba de elogios llamándolo "héroe del talento”, "triunfador del trabajo" y, a la vez, lo ubicaba entre los "grandes benefactores de la humanidad”. ${ }^{26}$ Díaz hizo referencia también al aporte social de los fonógrafos calificándolos de “maravillosos aparatos” que habían permitido “perpetuar” “la cariñosa voz de los seres amados reproduciendo todos los

23 Edison le había enviado un fonógrafo a Díaz como obsequio. Véase Daily Pacific Commercial Advertiser, Honolulu (27 dic. 1889), p. 2.

24 Koegel, "Grabaciones tempranas de música y músicos mexicanos”, p. 66.

25 Koegel, "Grabaciones tempranas de música y músicos mexicanos”, p. 66.

26 Véase “Porfirio Díaz a Thomas Edison”, grabación de 1909, en http:// www.gutemberg.com/etext/10255. Agradezco a John Koegel por esta referencia. 
ritmos, todos los acentos y todas las modulaciones del lenguaje humano". ${ }^{27}$

No siempre la utilidad epistolar del fonógrafo se tomó como un asunto muy serio. El rotativo Cómico publicó una secuencia de dibujos donde se desarrollaba una "declaración de amor por fonógrafo". La escena, construida a partir de códigos propios del humor mexicano, concluye con la rendición de la dama abrazada a la máquina, mientras escucha el mensaje de su amado, cuya jocosidad pudo consistir en la referencia fálica del "tubo del aparato". El amado confesaba: "yo la adoro a usted y si usted no me es indiferente y quiere hacerme dichoso, acuda usted a mis brazos, a oír mi tubo". En el segundo cuadro de la secuencia, se aprecia un parlamento de la desesperada amante que puede ser mucho más revelador sobre los usos sociales del fonógrafo: “ya no puedo contenerme. Que Edison sea el intérprete de mi amor y que diga usted que $[\ldots]$ ". ${ }^{28}$

La frase, en diálogo con una gran cantidad de noticias publicadas en la prensa, nos muestra una sociedad en la cual, como plantea Jonathan Crary, "cualquier diferencia entre vida y técnica comienza a evaporarse". ${ }^{29}$ En esta época, los inventores, artífices de su mito, constantemente respaldado por la opinión pública impresa, dejan de ser aburridos y locos señores enclaustrados en las universidades, para convertirse en figuras heroicas de una modernidad que los reivindica y los necesita.

27 “Porfirio Díaz a Thomas Edison”, grabación de 1909, en http://www. gutemberg.com/etext/10255.

${ }_{28}$ Cómico, México (25 mar. 1900), núm. 12, t. V, sin paginar.

${ }^{29}$ CRARY, Suspensiones de la percepción, p. 22. 
Pero el correo no fue el único rubro de explotación atribuido al invento. El periódico El Partido Liberal publicó, para marzo de 1892, una noticia que incidiría en el mundo de la juguetería: la invención de una muñeca fonográfica. Llevando en su interior un pequeño fonógrafo, este juguete de "fin de siglo" podía hablar "como una persona natural". La noticia también auguraba la existencia de otras muñecas capaces de "pronunciar discursos filosóficos", "entonar cancioncillas", "recitar versos" y hasta citar a Emilio Zola. También aquí, como se planteó anteriormente, quedaban eliminados los límites entre la ciencia y la vida ordinaria, en una relación donde la primera respondía a la transformación y mejoramiento de la existencia cotidiana. En este sentido, se afirmaba la importancia de la muñeca fonográfica en la unidad de los núcleos familiares ya que "la muñeca que se contentaba con decir papá y mamá era ya del todo insuficiente. Llegaba a ser degradada, á medida que los lazos de familia se debilitaban más y más". ${ }^{30}$ Estos cambios tecnológicos, daban cuenta de lo que el articulista calificaba como una "revolución bienhechora". Sin embargo, es posible que el interesante invento, a pesar de ser deseado por niñas de todos los estratos, sólo haya sido disfrutado por aquellas que pertenecían a los grupos de mejor posición económica.

Las aplicaciones del fonógrafo también comenzaron a ser pensadas en torno de los problemas de la atención, cuya centralidad en los debates científicos se consolidó en la segunda mitad decimonónica. De acuerdo con Jonathan Crary, entre 1810 y 1840 se produjo una ruptura con el régimen visual clásico, con lo cual "el funcionamiento de la

30 El Partido Liberal, México (4 mar. 1892), p. 2. 
visión pasó a depender de la constitución fisiológica, compleja y contingente del observador, convirtiendo la visión en algo defectuoso, poco fiable, o como se llegó a decir, en algo arbitrario". ${ }^{31}$ Los diversos debates llevados a cabo en la prensa revelan que la percepción visual no fue el único problema tratable para la medicina decimonónica. A los fonógrafos se les encomendó la tarea de mejorar las deficiencias auditivas.

En 1898, el periódico El Mundo transmitió a la sociedad mexicana una asombrosa aplicación médica del fonógrafo, vinculada al tratamiento médico de la atención "audible": "la curación de los sordos y sordo-mudos". El artículo daba a entender, sobre la base de este padecimiento específico, que las deficiencias en el organismo humano eran curables en la medida en que avanzara la tecnología apropiada. Las ventajas de un microfonógrafo eran descritas de la siguiente forma:

Estamos pues en posesión de un aparato automático de hablar, fácilmente manejable para los ejercicios auditivos necesarios á la recuperación y aprendizaje de la palabra en los sordomudos cuya curación va á poder emprenderse y realizarse sobre nuevas bases, pues hasta ahora por falta de medios apropiados se había descuidado el órgano defectuoso del oído abandonado á su falta nativa ó accidental de funcionamiento. ${ }^{32}$

Tres años más tarde el rotativo especializado La Medicina Científica dio a conocer la factibilidad del fonógrafo en el tratamiento de la hipnosis "a distancia”:

31 CRARY, Suspensiones de la percepción, p. 21.

32 El Mundo, México (16 ene. 1898), p. 42. 
Consiguientemente, cuando el médico pudiese hallarse junto al enfermo en todos los casos precisos, y no creyese conveniente recurrir a la ayuda de un tercero, deberá examinar si es el caso de ejercer su obra benéfica desde lejos y recurrir al hipnotismo á distancia con los medios de transmisión que le ofrecen los sistemas á distancia entre una persona y otra. Y los medios de que podremos comúnmente disponer son el envío de una carta, el teléfono, el telégrafo y aun el fonógrafo, última de las maravillas edisonianas. ${ }^{33}$

En este caso, el artefacto no sólo posibilitaba la veracidad del testimonio, la privacidad de la recepción y la repetición confiable del mensaje, como se aclaró anteriormente, sino que también acortaba las distancias comunicativas entre el médico y el paciente, sin la presencia física del tratante, tal como ocurrió en el ámbito musical con la figura del intérprete. ${ }^{34}$ En una visión diacrónica la capacidad de separar la voz y el cuerpo también propició la preservación y repetición de la primera, más allá de los límites mortales del segundo. Es en esta "larga” duración que los fonógrafos dejaron de ser máquinas de actualidad, para convertirse en instrumentos de memoria y de nostalgia.

Debe precisarse que las múltiples especulaciones sobre lo que muchos llamaron el mejor invento de la época no siempre fueron unidireccionales en torno de sus beneficios. Por ejemplo, El Monitor Republicano, contraponiendo la experiencia del receptor ordinario a las aseveraciones científicas, refirió el caso de Felipe Pérez, un “individuo" que, de acuerdo con una fuente periodística sin precisar,

33 La Medicina Científica, México (1º abr. 1895), p. 104.

34 Gitelman, “Reading Music”, p. 265. 
se quejó de "haberse enfermado de los oídos después de haberse aplicado á los conductos auditivos los audífonos de un fonógrafo". A pesar de no ofrecer otras pruebas acerca del suceso, el breve comentario de la noticia termina sentenciando que "realmente esos audífonos pueden ser vehículos de varias enfermedades contagiosas". ${ }^{35}$

Estos debates sobre la aplicación del fonógrafo a la vida nacional alcanzaron otros rubros como la jurisprudencia, donde la máquina serviría para grabar los juicios e incluso para dejar constancia de los testamentos. Sin embargo, conforman sólo una cara de la moneda. Otras incógnitas, mucho más difíciles de rastrear, se esconden tras las estrategias de posesión y consumo.

\section{ESTRATEGIAS PARA POSEER.}

UNA MIRADA AL ALQUILER DE LOS FONÓGRAFOS

En las primeras décadas del siglo xx, la imprenta capitalina Guerrero, ubicada en la calle Correo Mayor número 101, publicó un impreso donde se anunciaban unas coplas de fonógrafo. El dibujo que acompañaba la letra de una canción, posiblemente grabada en algún disco de la época, no había sido obra de un dibujante mexicano, sino que formaba parte de una campaña publicitaria de la empresa de Thomas Edison. ${ }^{36}$ En el mensaje visual, ahora consumido por el público capitalino mediante un formato de amplia circulación, se mostraba una imagen vertical del consumo fonográfico: una pareja de ricos propietarios que enseñan a sus

35 El Monitor Republicano, México (3 mar. 1895), p. 3, col. 2.

${ }^{36}$ Gitelman, "Reading Music”, p. 280. 
empleados domésticos el invento edisoniano. ¿En qué medida sería posible contradecir esta imagen? ¿Fueron las clases altas las únicas propietarias del invento edisoniano?

Con un costo aproximado de entre 150 y 400 pesos, al menos cuando estaban nuevos, los fonógrafos podían considerarse artículos de lujos para el nivel de vida promedio de la época. ${ }^{37}$ Aun así la publicidad comercial, inserta en las páginas de la prensa nacional, no dejó de buscar a un público con bajos ingresos. En un interesante artículo sobre la revista CROM, Engracia Loyo analiza cómo la publicación, a pesar de estar dirigida a un público obrero, exhortaba a sus lectores a adquirir productos que superaban, muchas veces de forma exagerada, el valor de sus sueldos. Además de terrenos en elegantes zonas de la ciudad, lujosas prendas de vestir, novedosos efectos electrodomésticos y muebles exclusivos, la CROM publicitó la venta de "fonógrafos al contado" con un valor entre 80 y 400 pesos, importe que, según la historiadora mexicana, oscilaba "entre uno y medio y siete salarios mensuales". ${ }^{38}$

Loyo, "Gozos imaginados, sufrimientos reales".

${ }^{38}$ Loyo, "Gozos imaginados, sufrimientos reales", p. 357. 


\section{Imagen 1}

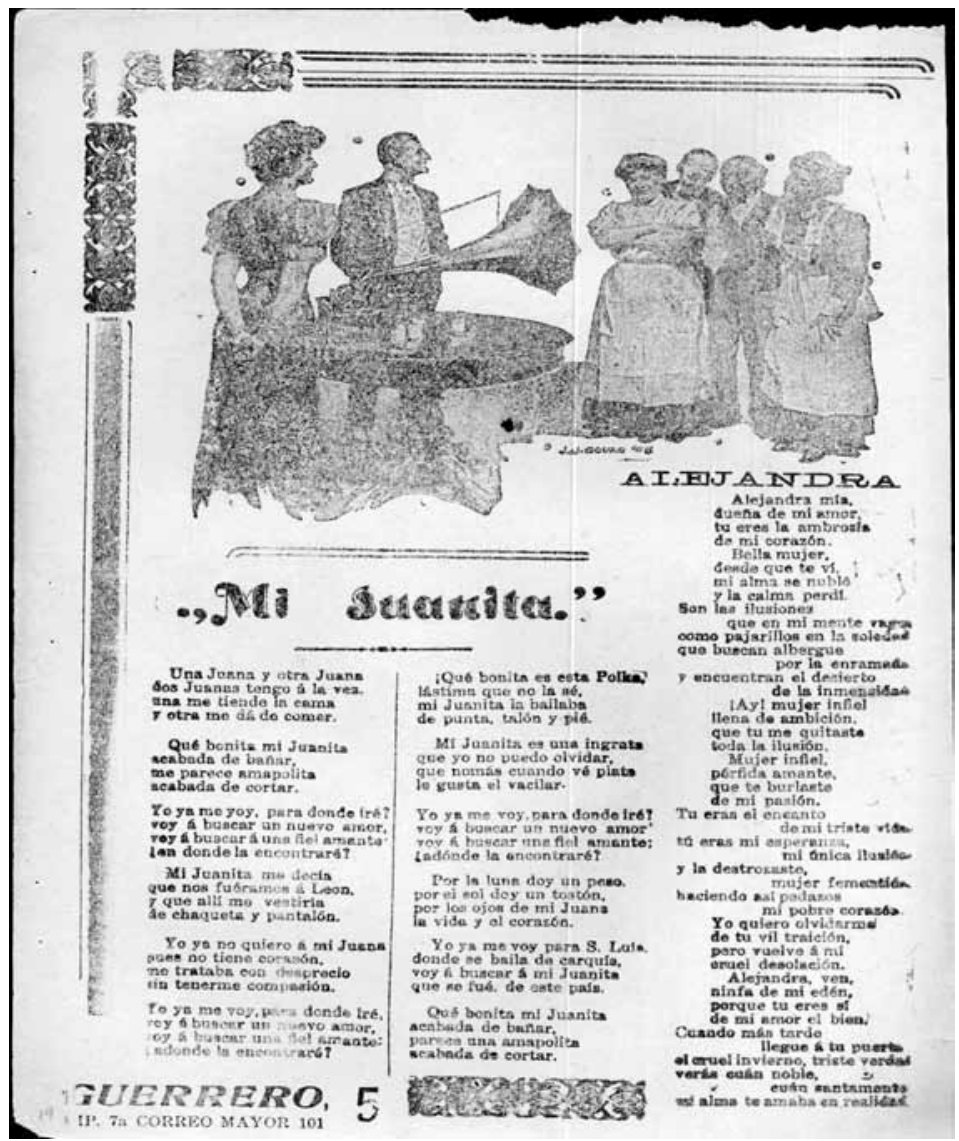

Hoja suelta de la imprenta Guerrero. ${ }^{39}$

39 Colección de hojas sueltas de la imprenta de Eduardo Guerrero, con "Corridos históricos de la revolución mexicana desde 1910 a 1930 y otros notables de varias épocas”. Consultado en la Colección Especial de la biblioteca de El Colegio de México. 
A pesar de los altos precios, ${ }^{40}$ la información recopilada en México nos conduce a reconocer que, en algunos casos, las clases medias y populares tuvieron acceso a las máquinas. Este desfase entre el valor monetario de los artefactos y la presunta adquisición de los sectores con medios y bajos recursos, conlleva a proponer una cuestión metodológica interesante: ¿mediante cuáles estrategias estos grupos pudieron acceder al codiciado invento?

Las fórmulas que permitieron una ampliación de los usos sociales de los fonógrafos en la vida cotidiana hacia sectores sin abundante solvencia fueron múltiples y pueden escapar a los moldes de la teoría y la imaginación del historiador. Por ejemplo, en los archivos judiciales se conservan casos de robo y estafa que permitieron la circulación de las máquinas hacia sectores que en general tenían bajos recursos. También es posible pensar en estrategias comunitarias y familiares, como la compra colectiva de los artefactos.

En otras situaciones, la posibilidad de convertirse en propietario dependió más de la suerte que de las posibilidades económicas y las prácticas ilegales. Éste fue el caso de las rifas, las cuales le permitían a las empresas comercializadoras aprovechar una demanda con bajos recursos y mucha fe.

${ }^{40}$ En la década de 1920, de acuerdo con la información recopilada por Engracia Loyo, un "choufer" ganaba menos de 25 pesos mensuales, un burócrata 27 con descuento y un cobrador de camión 35 pesos, mientras que un "empleado de oficios varios" podía llegar a percibir 60 pesos. Aunque no existía un salario mínimo obligatorio, la Secretaría del Trabajo, Industria y Comercio estimaba, en un estudio llevado a cabo a fines del periodo, que era de 1.50 pesos diarios. También se revelaba que el ingreso promedio de los obreros ferroviarios era de 80 pesos, aunque un trabajador especializado podía ganar 156 pesos al mes. Loyo, “Gozos imaginados, sufrimientos reales", p. 374. 
El periódico capitalino El Popular se hizo eco en 1902 de una rifa propuesta por J. Morales Cortázar y Cía. Por sólo 10 pesos, las personas de bajos ingresos podían lograr el sueño de convertirse en propietarios de un sofisticado fonógrafo y varias decenas de discos:

Regalamos por cada diez pesos al riguroso contado, neto, un billete para la rifa de un fonógrafo legítimo de Edison, marca Triunfo, último modelo con Micro-reproductor Bettini (propio para familia), y dotado con 36 fonogramas (impresionados en nuestro gabinete), ó su equivalente en otra clase de fonogramas, ó del mismo fonógrafo equipado con todos sus accesorios necesarios para explotarlo, incluyendo una dotación de cincuenta fonogramas de nuestra impresión. ${ }^{41}$

En ocasiones los concursos donde se sorteaban fonógrafos podían tener una complejidad mayor. Por ejemplo, la cervecería Moctezuma organizó una rifa de la XX: los concursantes debían comprar cervezas pertenecientes a la marca; por cada caja de bebida comprada se entregaban dos boletos, por la mitad se recibía uno. También se daba la posibilidad de canjear 30 corcholatas por un billete, cambio que podía hacerse a cualquier hora hábil en el establecimiento comercial La Perla de La Paz. Una máquina de coser New Home, un juego de muebles austriacos y un fonógrafo portátil Victor eran los premios prometidos. ${ }^{42}$

En este apartado, lejos de agotar el estudio de las más diversas estrategias adquisitivas de la época, se prefiere profundizar en un fenómeno específico: el alquiler. Tal elección

${ }_{41}$ El Popular, México (domingo 6 abr. 1902), sin paginar.

${ }^{42}$ Boletín de Información, Baja California (oct. 1928), p. 4. 
no sólo se fundamenta en la riqueza informativa hallada en los archivos mexicanos, sino también en las peculiaridades de una práctica escasamente abordada por la historiografía y con matices particulares.

En la década de 1920, la Compañía Industrias Unidas, cuyas oficinas tenían sede en la calle Balderas, adoptó una táctica que le permitía atraer a un público incapacitado de comprar al contado las "máquinas del sonido". El alquiler permitía que los arrendatarios, y seguramente sus familiares y vecinos, usufructuaran los servicios de los fonógrafos más avanzados de la época.

Gracias al atraso del pago de los clientes y a las demandas judiciales promovidas por la empresa, contamos con algunos “contratos por alquiler”. Estos documentos, de indiscutible riqueza histórica, permiten dilucidar las cláusulas establecidas en los convenios, el costo de las rentas, así como el nombre y la residencia de algunos clientes.

Sabemos que el 9 de marzo de 1923, Rosa A. de Acevedo, residente en la calle Plaza de Santiago, número 83, firmó un contrato de arriendo con la compañía Industrias Unidas. 40 pesos fue el pago inicial por un fonógrafo Magnatone estilo I. La clienta se comprometió a ingresar 20 pesos mensuales por tiempo indefinido. ${ }^{43}$ Un día después, el ciudadano Pablo Flores se dirigió hacia las mismas oficinas con un propósito semejante. Esta vez el arrendatario aceptó pagar 40 pesos en el momento de la firma del convenio, así como otros 10 pesos semanales, para llevarse a su casa, ubicada en la calle Hidalgo, número 10, un fonógrafo Magnatote

${ }^{43}$ AGN, Tribunal Superior de Justicia del Distrito Federal, c. 1864, fol. 336779 . 
estilo IV..$^{44}$ Ambos clientes pagaron precios iniciales similares. Esto no ocurrió dos meses más tarde, exactamente el 15 de mayo, cuando José Preve firmó su contrato. ${ }^{45}$ Él logró rentar un Magnatote estilo I por sólo 16 pesos de pago inicial y otros 5 de manera decenal "durante el tiempo que conserve en su poder el fonógrafo”. Es posible que Preve haya recibido un mejor trato por sus cualidades negociadoras o por un cambio en la estrategia de la empresa, sin embargo, el elemento reflejado en el contrato que marca la diferencia con los otros clientes es el modelo del fonógrafo alquilado. Mientras Pablo Flores y la señora de Acevedo seleccionaron un Magnatone estilo IV, Preve se contentó o sólo pudo pagar inicialmente un modelo menos sofisticado.

Resulta válido pensar que para la década de 1920 las fronteras de la distinción social no se tendieran sólo en la posesión de un fonógrafo, como se refleja en el grabado de la imprenta Guerrero, sino en el tipo de modelo adquirido. La competencia tecnológica en el perfeccionamiento del aparato generaba esta velocidad en los cambios de estilo, a la que sólo los más solventes podían adaptarse.

Al parecer, para 1924 la compañía Industrias Unidas introdujo otra fórmula. Además de los fonógrafos, alquilaría discos. Así, cuando el 3 de marzo de 1924 Zenaido Hernández, vecino de la calle Moctezuma, número 52, en Tacuba, se dirigió a Balderas para rentar un Magnatone estilo I, también integró en su convenio 18 discos. ${ }^{46}$ Lo

${ }_{44}$ AGN, Tribunal Superior de Justicia del Distrito Federal, c. 1864, fol. 336778 .

${ }^{45}$ AGN, Tribunal Superior de Justicia del Distrito Federal, c. 1864, fol. 336731 .

${ }^{46}$ AGN, Tribunal Superior de Justicia del Distrito Federal, c. 1890, 
mismo acordó Guadalupe G. viuda de Echegaray, residente en la calle Aquiles Serdán, número 29 en altos, quien alquiló un Magnatone estilo III y dos discos. ${ }^{47}$ En caso de pérdi$\mathrm{da}$, aclaraba el contrato, la viuda debía pagar 150 pesos por la máquina reproductora y 5 más por ambos discos.

El compromiso de pagar íntegramente el fonógrafo y en los últimos casos también los discos quedaba establecido en todos los convenios. La cláusula correspondiente lo refería de esta manera: "si faltara el arrendatario al pago puntual de cualquier alquiler cláusula, sea cual fuere el motivo, la Compañía podrá dar por terminado el alquiler, y por lo tanto, exigir la devolución del fonógrafo, o a falta de ella, el pago inmediato de su precio". En este sentido, siempre se acordaba el precio íntegro del fonógrafo. Éstos fluctúan, en el marco de los casos estudiados, entre 80 pesos, valor del Magnatone I rentado por Preve, hasta 200 pesos, precio fijado para la máquina alquilada por la viuda de Acevedo. No obstante, los precios podían duplicar la última cifra si se trataba de un modelo más sofisticado. Por ejemplo, el señor Everardo S. de Montellano, vecino de la calle I de Zacatecas, número 4, rentó en febrero de 1923 un Magnatone estilo V, valorado en 500 pesos. ${ }^{48} \mathrm{Si}$ el arrendatario deseaba convertirse en propietario debía pagar el precio fijado y se le reconocía el monto de las cuotas por alquiler: "El arrendatario podrá hacer suyo el fonógrafo pagando a la compañía, el precio fijado en la cláusula anterior, y en este

fol. 342239 .

47 AGN, Tribunal Superior de Justicia del Distrito Federal, c. 1890, fol. 342241 .

48 AGN, Tribunal Superior de Justicia del Distrito Federal, c. 1890, fol. 342240 . 
caso del precio se abonarán al arrendatario las cantidades que haya cubierto como alquiler". ${ }^{9}$

En los casos señalados la empresa intentó controlar la ubicación de los fonógrafos alquilados, estipulando en la primera cláusula de los contratos la siguiente orientación: "El arrendatario recibe en perfecto estado el fonógrafo objeto de este estado, obligándose a conservarlo en su propia casa como cosa alquilada y para su uso particular". Indudablemente, la permanencia de los artefactos en el ámbito espacial de las viviendas contribuía a la adecuada conservación de las máquinas, pero era el subarriendo la mayor preocupación de la empresa. Tal acción, además de generar la sobreexplotación de los fonógrafos, le restaba potenciales clientes a la compañía.

En algunos contratos, esta especificación se aclaraba textualmente. En el documento firmado por José Alberto Tapia el 13 de septiembre de 1922, el arrendatario acordaba que no podía "transmitir el dominio" del Magnatone estilo V alquilado, como tampoco traspasarlo, venderlo ni subarrendarlo. ${ }^{50}$ El subarriendo no resulta una hipótesis desestimable. Éste pudo llevarse a cabo de varias formas: la primera sería el traslado del fonógrafo hacia otras casas del barrio para ser rentado por un día o varios; la otra forma dependía de una demanda de personas capaces de pagar, por determinado tiempo la escucha de los discos. Ambas prácticas resultaban factibles en el plano económico para un público incapaz de

49 AGN, Tribunal Superior de Justicia del Distrito Federal, c. 1890, fol. 342240 .

50 AGN, Tribunal Superior de Justicia del Distrito Federal, c. 1890, fol. 336778. También se expresaba que la máquina debía conservarse en su "propia casa" "como cosa alquilada y para su uso particular". 
pagar los arriendos mensuales y los pagos iniciales exigidos por las compañías.

Sería difícil precisar que las personas que se acercaron a las empresas para alquilar fonógrafos lo hicieron pensando desde el comienzo en la posibilidad de incumplir el arrendamiento y quedarse con las máquinas. Lo cierto es que los precios observados en los contratos continúan siendo altos para los trabajadores con salarios más modestos. En estas circunstancias es posible pensar en la factibilidad de la renta en dos sentidos. Por una parte, servía para disfrutar el artefacto mientras se pagaba a plazos, es decir, una especie de crédito sin intereses; por otro lado, podemos sospechar que muchos clientes pudieron rentar las máquinas para alguna actividad especial como una boda o un cumpleaños. No se descarta que, en el caso de los menos solventes, se recogiera dinero entre los familiares e invitados para el alquiler. ${ }^{51}$

No obstante, puede señalarse que existieron opciones para comprar fonógrafos nuevos o de uso a precios más favorables. Por ejemplo, un anuncio publicado en 1909 por el Mexican National Phonograph, con sede en Tacuba, daba a conocer un amplio rango de precios de los fonógrafos Edison que oscilaba entre 32 y 275 pesos. Además de los artefactos, también se anunciaban los fonogramas con costos inferiores a la tasación establecida en los contratos de alquiler de la compañía Industrias Unidas: fonogramas Amberol a 1.30 pesos, fonogramas Edison comunes a 1 peso y fonogramas de ópera, 2 pesos. ${ }^{52}$

\footnotetext{
${ }^{51}$ Agradezco a la doctora Viviana Bravo Vargas por sus valiosos comentarios sobre este tema.

${ }^{52}$ El Mundo Ilustrado, México (25 abr. 1909), sin paginar.
} 
Otra de las opciones para el público con menos recursos fueron los remates de fonógrafos usados en el marco de procesos judiciales. Por ejemplo, el 8 de abril de 1925, el juzgado numerario del distrito de Mérida, en Yucatán, anunció el remate de un fonógrafo al asequible precio de 20 pesos..$^{53}$ Éste, junto con otros bienes, correspondía al "juicio ordinario mercantil promovido por Alejandro Peña contra Diego Domínguez". Otro juicio, esta vez catalogado como "ejecutivo mercantil" y celebrado en 1922, promovía el remate de un fonógrafo Victor en 50 pesos. ${ }^{54}$ Un anuncio, publicado en el Diario Oficial del Gobierno Socialista del Estado de Yucatán, tal como sucedió en el caso anterior, proclamaba lo siguiente:

Se hace saber al público, en convocación de postores, que en el juicio ejecutivo mercantil seguido por Eusebia Poot contra Francisco Oropesa López, se ha señalado el día treinta del actual, las once horas del día y el local de este Juzgado para que tenga lugar el remate, en primera almoneda, de los siguientes bienes: un armazón con vidrios y el mostrador con vidriera, avaluado en $\$ 150.00$; un ropero de roble con lunas, avaluado en $\$ 100.00$; un juego de muebles americanos compuesto de catorce piezas, avaluado en $\$ 170.00$; una cama de roble avaluada en

53 Diario Oficial del Gobierno Socialista del Estado de Yucatán, Mérida (8 abr. 1925), p. 13.

${ }^{54}$ En otros casos no eran los discos ni las máquinas para reproducirlos los ofrecidos en los remates judiciales. Como resultado de un juicio ejecutivo mercantil llevado a cabo en un juzgado civil capitalino en 1914, se ofrecía al público "una comodita de encino, de una puerta para guardar discos de fonógrafos", por el precio de 10 pesos. Diario de Jurisprudencia, México (martes 31 mar. 1914), p. 8. 
$\$ 100.00$; un tocador de roble con luna, avaluado en $\$ 80.00$, y un fonógrafo "Víctor, “ avaluado en $\$ 50.00 .55$

En otros estados también se abrió dicha posibilidad de compra. El martes 4 de junio de 1912, se anunció en el juzgado de Monterrey, para el próximo día hábil, el remate de un fonógrafo Edison. El anuncio no dio detalles de la valuación del aparato embargado en un juicio ejecutivo mercantil. ${ }^{56}$

Sin embargo, no siempre los fonógrafos embargados en los tribunales tenían precios bajos. Por ejemplo, en 1919 el Diario Oficial de Yucatán anunció el remate de un fonógrafo Victor valuado en 150 pesos, fruto de un juicio civil "seguido por el señor Ramón Bazán contra el señor Marcos Duarte Villamil". 57

Detrás de cada compra y alquiler se esconde un mundo de estrategias económicas y deseos de posesión que una vez más dan la razón a autores que, como Néstor García Canclini, aseveran que "el consumo sirve para pensar". ${ }^{58} \mathrm{Sin}$ embargo, la necesidad de acceder a los artefactos no es suficiente para intentar completar el complejo e inagotable rompecabezas de la recepción. En este sentido, las denuncias por el retraso en el pago del alquiler de los fonógrafos, anteriormente estudiadas, poseen algunas limitaciones y beneficios para el análisis histórico. Si bien omiten informaciones necesarias para determinar la clase social de los deudores, como

${ }_{55}$ Diario Oficial del Gobierno Socialista del Estado de Yucatán, Mérida (28 sep. 1922), p. 10.

${ }^{56}$ Periódico Oficial del Gobierno Libre y Soberano de Nuevo León, Nuevo León (4 jun. 1912), p. 16.

57 Diario Oficial del Gobierno Socialista del Estado de Yucatán, Mérida (27 sep. 1919), p. 4289.

${ }^{58}$ Néstor García Canclini, "El consumo sirve para pensar”. 
podría ser el nivel de ingresos y el oficio que ocupaban, por otro lado cabe precisar que las direcciones de los implicados y la necesidad de acudir al alquiler permiten deducir la existencia de clientes que, tal vez por dificultades de solvencia, no pudieron pagar una máquina al contado. ${ }^{59}$

\section{TESTIMONIOS PARA PENSAR LA RECEPCIÓN.}

EN BUSCA DE UNA HISTORIA POSIBLE

Al pensar los usos cotidianos del fonógrafo, no debe olvidarse una de sus particularidades: en comparación con la radio y la televisión, el funcionamiento de estos artefactos permitía un consumo mucho más crítico, ya que el receptor podía elegir, cuestionar luego de escuchar y sobre todo decidir la repetición. Tales posibilidades fueron ofrecidas a los receptores décadas más tarde por otras innovaciones como la cinta de cassette, invento que, según reconoce Eric Hobsbawn, trajo consigo una revolución en el mundo musical y la cultura política de los años sesenta. ${ }^{60}$

Pero, ¿cómo encontrar los rastros de la recepción fonográfica? La dificultad de la pregunta ayuda a entender por qué los historiadores, en su mayoría, se sienten cómodos estudiando los discursos producidos por las industrias culturales, sin ni siquiera intentar reconstruir los procesos de consumo o al menos preguntarse por su existencia. El estudio de esta otra cara de los procesos de comunicación continúa siendo el mayor reto de la historiografía latinoamericana, no sólo por la dificultad y el esfuerzo que reclama

${ }^{59}$ Claro está que la ubicación de las viviendas pudo ser inventada, sobre todo si desde el momento de firmar el contrato se intentaba incumplirlo. ${ }^{60}$ Hobsbawm, Historia del siglo XX, p. 496. 
la búsqueda de estas fuentes, sino por la riqueza metodológica y las nuevas preguntas de investigación que puede mostrarnos este mundo de estrategias insospechadas.

Lizabeth Cohen puede considerarse entre las pocas historiadoras que logró visualizar el complejo mundo del consumo cultural fonográfico, exponiendo sus herejías metodológicas. En su trabajo "Encountering Mass Culture at the Grassroots: The Experience of Chicago Workers in the 1920s", la estudiosa estadounidense pudo reconstruir las experiencias de diferentes grupos de consumidores y demostrar cómo los usos sociales cotidianos de medios como el cine, la radio y los fonógrafos revelan experiencias que contradicen la repetida homogeneidad de la cultura de masas. Para lograr este objetivo, propuso abandonar la "escena nacional", debido a la dificultad de encontrar documentación suficiente sobre el consumo, para concentrarse en el Chicago de los años veinte, teniendo en cuenta la amplia documentación producida por las investigaciones de sociólogos, politólogos, trabajadores sociales y estudiantes durante esta década. Gracias a los testimonios de obreros mexicanos, polacos e italianos y sus descendientes, Cohen evidenció, en una breve pero sustancial exposición, que estos actores sociales consumían en sus hogares y reuniones comunitarias grabaciones en sus idiomas originarios. Por tanto, los fonógrafos, lejos de propiciar una "americanización” del consumo, permitieron a estas familias mantener viva su cultura ("in story atter story they related how buying a victrola helped keep Polish or Italian culture alive by allowing people to play foreignlanguage records, often at ethnic social gathering”); incluso, como señala la autora, 
se llegaron instalar tiendas para comercializar discos con música mexicana. ${ }^{61}$

¿Hasta qué punto es posible seguir las huellas al consumo fonográfico en México? Con el propósito de comenzar a reconstruir esta historia, pletórica de silencios y esparcida en fragmentos, proponemos revisar algunos relatos y datos estadísticos de la época. A diferencia de los expedientes judiciales sobre el retraso del pago de alquiler estudiados en el apartado anterior, en estas fuentes se muestra un registro más amplio de los consumidores y, en algunas ocasiones, se llegan a ilustrar sus experiencias ante el fonógrafo en escenarios concretos.

Por ejemplo, el antropólogo y etnógrafo Alfonso Villa Rojas, nacido en 1898, legó importantes testimonios manados de sus observaciones de campo en el mundo rural yucateco, que ayudan a probar que los sectores más marginales sí aprovecharon las diferentes ofertas que propiciaba el mercado mexicano. Con un tono matizado por la queja, Villa Rojas constató la recepción de los fonógrafos por los indígenas, cuyo poder adquisitivo era favorecido por la cosecha del chicle:

En 1936 y 1937 el chicle fue vendido a 44 pesos quintal (5 marquetas), precio que a los nativos parecía demasiado bajo en comparación con el de años anteriores [...]. No teniendo los indígenas aspiraciones de mejoramiento social, malgastaban el dinero así obtenido [en la explotación del chicle] en grandes borracheras o artículos superfluos, tales como fonógrafos, máquinas de coser o lámparas de mano, todo lo cual quedaba pronto inservible por falta de costumbre y destreza en su manejo. ${ }^{62}$

61 Cohen, "Encountering Mass Culture at the Grassroots”, pp. 8-9.

62 Villa Rojas, “Los mayas del actual territorio de Quintana Roo”, p. 162. 
Esta apreciación no captó un fenómeno particular y asilado. Un estudio realizado en las aéreas rurales mexicanas entre 1931 y 1932 reveló datos interesantes sobre la composición racial de las comunidades y la presencia de elementos de la cultura material “moderna”, entre ellos los fonógrafos. El estudio, llevado a cabo en 703 comunidades de indios reveló que $53.8 \%$ de éstas poseían los artefactos. Por su parte la encuesta de 956 comunidades mestizas y blancas develó, contra todo pronóstico, que sólo 41.5\% de estos asentamientos contaban con fonógrafos, es decir, $12.3 \%$ menos respecto al primer grupo. ${ }^{63} \mathrm{Sin}$ embargo, un elemento decisivo que escapa a las tablas estadísticas es la recepción colectiva de los aparatos, relacionada con espacios, prácticas festivas y redes de clientes entre los miembros de la comunidad.

Los fonógrafos también ambientaron las escenas de la Revolución. En el marco del combate y en las tertulias de campamento fueron un medio de relajamiento ante los pesares de la guerra. Un testigo de la batalla de Juárez recuerda cómo soldados y trabajadores, gracias al entretenimiento de "guitarras, fonógrafos y pianos", no sintieron el peligro generado por el constante enfrentamiento armado:

Mientras los unos ocupaban los techos y ponían fuera de combate a los tiradores federares de las torres y de las azoteas, otros horadaban las paredes de adobe y los demás fumaban, comían lo que podían encontrar y algunos entretenían a los trabajadores tocando guitarras, fonógrafos, pianos o cualquier otro instrumento de música que se encontraban en las casas. ${ }^{64}$

63 Tannembaum, “Technology and Race in Mexico”, p. 383.

${ }^{64}$ McGowan (coord.), La Revolución Mexicana, p. 169. 
En algunos casos, la circulación y recepción de los artefactos se asoman a la memoria de los principales líderes del proceso revolucionario. El general Lázaro Cárdenas, por ejemplo, recordó que en 1908 su padre, tras una estancia en la capital por asuntos médicos, llegó a su casa con un fonógrafo que ambientó, desde ese día, los festejos hogareños. Elementos como la circulación de los artefactos en un plano interestatal, así como la recepción colectiva de los discos, se entretejen en la trama de sus recuerdos de la siguiente manera:

A fines de 1908 mi padre padeció de la vista y se trasladó a la ciudad de México, en donde fue operado de un ojo. La operación la costeó su primo Ramón Pinedo, que radicaba en la capital. Volvió a Jiquilpan y nos trajo como regalo un pequeño fonógrafo de bocina. La tarde de ese mismo día se tocaron los discos, escuchando el primero, El cuarto poder. Fue una fiesta en toda la tarde y parte de la noche con la reunión de amistades y familiares que tomaron parte en el festejo, por el regreso de mi padre. ${ }^{65}$

Por su parte, John Reed aportó un interesante testimonio que señala el vínculo de los artefactos con la imagen de la Revolución. Cuando el general Tomás Urbina le pidió que lo retratara en el patio de su casa, ubicada en el poblado de Las Nieves, alguien trajo a propósito un fonógrafo para que ambientara la escena.

Durante la hora siguiente estuve tomando fotografías del general Urbina a pie, con espada y sin ella; el general Urbina cabalgando sobre tres caballos distintos; el general Urbina con su

${ }^{65}$ Cárdenas, Apuntes, p. 25. 
familia y sin ella; los tres niños del general Urbina, a caballo y a pie; la madre del general Urbina y su concubina; toda la familia armada con espadas y pistolas; también el fonógrafo - traído a propósito - y uno de sus niños sosteniendo un cartel donde estaba escrito con tinta: «General Tomás Urbina R.». ${ }^{66}$

Los artefactos también formaron parte del inventario hogareño de uno de los altos oficiales sureños. El 26 de noviembre de 1914, un reportero anónimo de El Sol y del Mexican Herald visitó la casa del general zapatista Maximino V. Iriarte, ubicada en Xochimilco. La descripción que el reportero publicó de la vivienda destruida por los carrancistas deja ver la presencia de un fonógrafo, calificada como indispensable, sin que desentonara de la humildad del recinto familiar, donde residían su mujer y un hijo. Fueron éstas sus palabras: "penetramos a la pequeña casa ubicada frente al Cuartel General. Ni lujos, ni cuadros, ni colgaduras: unas cuantas sillas, una mesa y el indispensable fonógrafo". ${ }^{67}$

La presencia y los efectos del invento edisoniano no siempre estuvieron del lado de los revolucionarios. Ante la invasión zapatista a las haciendas de Tenango y Santa Clara, a mediados de abril de 1913, los propietarios Luis y Joaquín García Pimentel habían encontrado en la diversión de los fonógrafos un medio mucho más eficiente contra la desesperación, que la posibilidad de confesarse y recibir la comunión. ${ }^{68}$ En esos días cercanos a la muerte, los hermanos García Pimentel, quienes sólo contaban con una guarnición de 10 soldados comandados por un oficial francés, levan-

66 ReED, México insurgente, pp. 49-50.

67 Pineda, La revolución del sur, p. 498.

68 Citado por Womack, Zapata y la Revolución Mexicana, p. 180. 
taron el ánimo escuchando "roncos discos de fonógrafos", con un repertorio que incluía "discursos patrióticos, escenas históricas, canciones y piezas de música" ${ }^{69}$

En el testimonio no se precisan los acontecimientos relatados en los discos. Sin embargo, debe señalarse que, desde inicios del siglo xx, las principales empresas disqueras estuvieron interesadas en grabar a cantantes populares y actores cuyas voces tocaran el alma patriótica del mercado mexicano. ${ }^{70} \mathrm{El}$ actor Julio Ayala fue una de esas estrellas teatrales que inmortalizaron en las placas acontecimientos trascendentales del devenir nacional, antes y durante el proceso revolucionario. La última batalla, el discurso recientemente pronunciado por el líder revolucionario, así como la memoria de la gesta anticolonial, forman parte de un amplio repertorio, patrocinado por la empresa estadounidense Columbia. ${ }^{71}$ Entre los discos que sobreviven podemos leer títulos como: Delirio y muerte del general Zaragoza, Tragedia de Aquiles Serdán, Discurso de Francisco I Madero en Puebla la noche del 18 de julio de 1911, Batalla del Monte de las Cruces, Escándalos en la Cámara de Diputados y en las calles de la México, Fusilamiento de Hidalgo, Resumen de la batalla de Ciudad Juárez, Batalla del 5 de mayo, Aviso del levantamiento al Ministro de la Guerra.

Estas obras formaban parte de un amplio catálogo de grabaciones realizadas en México por compañías estadounidenses

${ }^{69}$ Citado por Wомаск, Zapata y la Revolución Mexicana, p. 180.

70 Sobre el tema véase Koegel, "Grabaciones tempranas de música y músicos mexicanos".

${ }^{71}$ Las primeras pistas sobre los fonogramas de Julio Ayala las obtuve de un trabajo del periodista e investigador Pablo Dueñas. Véase Dueñas, "La magia del fonógrafo". 
como Victor, Columbia y Edison durante las primeras décadas del siglo $\mathrm{xx}$, las cuales abarcaron los más diversos géneros musicales. John Koegel marca "el inicio de la industria de grabaciones de música mexicana” en 1904, tomando como hecho fundacional el envío de un equipo de la Edison Company encabezado por el ingeniero George J. Werner. ${ }^{72}$ Sumado a ello, el investigador estadounidense señala que, antes de la expedición de Werner, "en algún momento alrededor de 1904, los cilindros y fonógrafos Edison que contenían muchos tipos de música hecha en los Estados Unidos ya estaban disponibles para su venta en diversos lugares del país" ${ }^{73}$

Un anuncio publicado el lunes 3 de noviembre de 1902 en el Semanario Literario Ilustrado abre nuevas interrogantes a las consideraciones de Koegel. Dos años antes de la visita de Werner, en el periódico capitalino se promovía la venta de algunos fonogramas de Julio Ayala sobre relevantes acontecimientos de la historia mexicana: "A toda persona que tenga fonógrafo se le recomienda que pasen á la cerca de Sto Domingo, núm 12, taller mecánico para aparatos eléctricos y científicos á comprar los fonogramas más acreditados de episodios históricos nacionales y de actualidad por Julio Ayala". ${ }^{74}$

72 En este empeño destacó la figura de Rafael Cabañas, gerente de la empresa en México, quien intervino en la selección de los "ejecutantes y el repertorio a grabar”. Durante la visita a la capital mexicana, Werner grabó 303 cilindros. La edición facsimilar de The Edison Phonograph Monthly revela, como muestra Koegel, un amplio repertorio conformado por "zarzuelas mexicanas y españolas, corridos, coplas populares de la escena de zarzuela mexicana, extractos de ópera, danzas vocales e instrumentales, valses, polcas, chotises y otras danzas de salón”. Véase Koegel, "Grabaciones tempranas de música y músicos mexicanos pp. 70-73.

${ }^{73}$ Koegel, "Grabaciones tempranas de música y músicos mexicanos", p. 70.

74 Semanario Literario Ilustrado, México (lunes 3 nov. 1902), p. 740. 
La primera parte de la serie de tres discos trataba la "salida de las tropas francesas de la capital de la república"; la segunda se dedicaba a la "prisión de Maximiliano en el convento de Capuchinas [Querétaro]", mientras el tercer disco se consagraba al "fusilamiento de Maximiliano, Mejía y Miramón en el Cerro de las Campañas”. A pesar de que el anuncio mostraba el interior del local donde se grababan los fonogramas y señalaba el nombre del actor protagónico, es decir, mostraba la escena de la ficción discursiva, en la vida cotidiana muchas personas creyeron que se trataba de las palabras de los verdaderos protagonistas.

\section{Imagen 2}

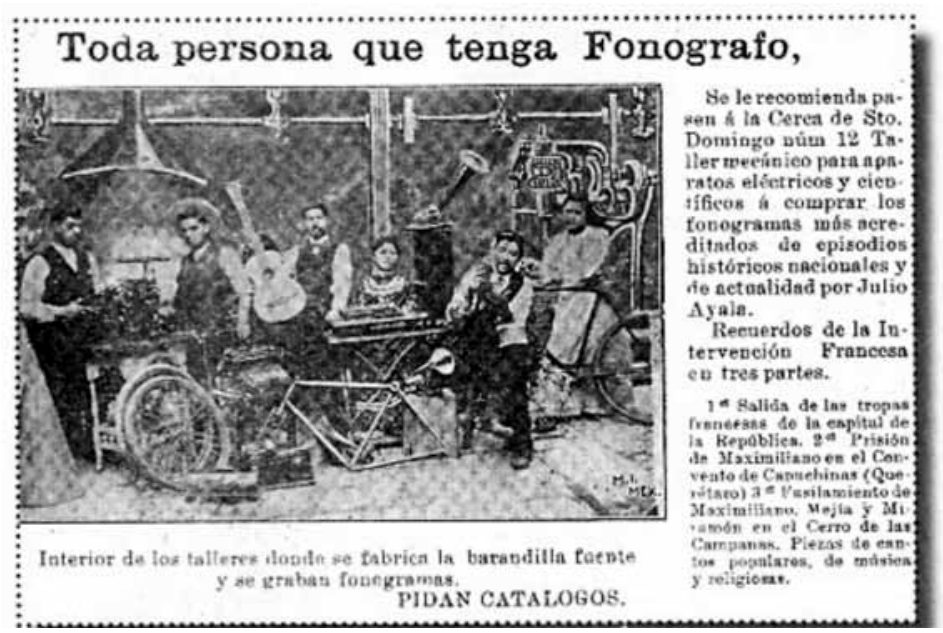

Promoción de los discos de Julio Ayala en el periódico Semanario Literario Ilustrado, $1902 .{ }^{75}$

75 Tomada de Dueñas, "La magia del fonógrafo”, 2010. 
La relación entre el nacionalismo y los fonógrafos atraviesa tanto los procesos de consumo como los de producción y circulación. Los discos transmitieron y generaron una memoria nacional que circuló hacia los sectores menos favorecidos y muchas veces analfabetos, una memoria donde el acontecimiento y la ficción se abrazaron y reelaboraron en los procesos heterogéneos del recuerdo popular. Sin olvidar, por supuesto, que se trata de una producción musical mediada por las compañías fonográficas estadounidenses, que vieron en los acontecimientos patrióticos una temática rentable, con un ávido mercado existente en el territorio nacional y las comunidades de inmigrantes mexicanos. Este mundo que escapa a las historias tradicionales y los manuales escolares muestra sus atisbos en las palabras de Ceferino Juárez, campesino nacido en 1902 en el municipio potosino Villa de Juárez:

Cuando tenía cinco o seis años ya le había aprendido la sonería a mi padre. Se me había grabado en la mente. En 1913 nos fuimos para Agua de En medio. Se vino la Revolución, y para el 15 ya no pudimos estar. Nos radicamos en Cerritos [...]

También andando con mi papá grabaron unos discos de fonógrafo, eran unos tubitos anchitos y larguitos; los metían en el fonógrafo y chillaban: sss sss ... se ponía uno las tripitas en los oídos. Eso fue en el año del 17. Ahí quedó la música grabada. Mi hermano la tenía, pero se le descompuso el motorcito. Todo quedó en nada, pero me quedé con la base más o menos de lo que él tocaba $[\ldots]^{76}$

76 Entrevista realizada por Eliazer Velásquez, fragmento tomado de Martínez, “Introducción del Fonógrafo en San Luis Potosí”, p. 18. 
Su testimonio también provoca la necesidad de ir en busca de otros testigos que informen sus experiencias fonográficas en la primera mitad del siglo xx. ¿Mostrarán estas memorias otras formas de utilizar los artefactos en la vida cotidiana que escaparon a los documentos escritos? ¿Acaso podrán revelar parte del amplio repertorio musical que circuló en los discos? ¿Quedarán restos de las cajas parlantes en las casas de los campos mexicanos, tal vez de adornos, de mesitas de noche o convertidas en improvisados instrumentos de percusión? ¿Cantarán aún los abuelos a los nietos aquellos corridos de Francisco Villa y Emiliano Zapata que escucharon en los discos de la Victor y Columbia, articulando una memoria política que escapa a los manuales de la historia oficial? Las interrogantes ponen fin a este primer intento por desentrañar una historia poco abordada, pero al mismo tiempo generan un compromiso con la continuidad de recorrer otras páginas, de indagar en nuevos archivos y, sobre todo, de grabar viejas voces. ${ }^{77}$

SIGLAS Y REFERENCIAS

AGN Archivo General de la Nación, México.

Bejarano, Ignacio

Actas de Cabildo del Ayuntamiento de la ciudad de México, 1887.

77 El rescate de los testimonios orales sobre la recepción de los fonógrafos constituye uno de los objetivos futuros de esta investigación. 
CÁRdenas, Lázaro

Apuntes, una selección, México, Universidad Nacional Autónoma de México, 2003.

Cohen, Lizabeth

"Encountering Mass Culture at the Grassroots: The Experience of Chicago Workers in the 1920s", en American Quaterly, 41; 1 (mar. 1989), pp. 6-33.

Crary, Jonathan

Suspensiones de la percepción. Atención, espectáculo y cultura moderna, Madrid, Akal, 2008.

Díaz Ayala, Cristóbal

Cuba canta y baila. Discografía de la música cubana, 18981925, San Juan, Fundación Musicalia, 1994. Consultado 3 de febrero de 2015 en http://latinpop.fiu.edu

Dueñas, Pablo

"La magia del fonógrafo", en www. ciudadanosenred.com.

García Canclini, Néstor

"El consumo sirve para pensar", en Consumidores y Ciudadanos. Conflictos multiculturales de la globalización, México, Grijalbo, 1995, pp. 41-55.

Gitelman, Lisa

"Reading Music, Reading Records, Reading Race: Musical Copyright and the U. S. CopyrightAct of 1909", en The Musical Quarterly, 81: 2 (verano 1997), pp. 265-290.

Gonzalbo Aizpuru, Pilar y Mílada Bazant

Tradiciones y conflictos. Historias de la vida cotidiana en México e Hispanoamérica, México, El Colegio de México, El Colegio Mexiquense, 2007. 
Hobsbawn, Eric

Historia del siglo xx, traducción de Juan Faci, Jordi Ainaud y Carme Castells, Buenos Aires, Crítica, 2002.

Koegel, John

"Grabaciones tempranas de música y músicos mexicanos”, en Discanto, Ensayos de Investigación musical, Veracruz, Universidad Veracruzana, 2008, t. II.

Loyo, Engracia

"Gozos imaginados, sufrimientos reales. La vida cotidiana en la revista Crom (1925-1930)”, en Gonzalbo Aizpuru y BAZANT, 2007.

Luhmann, Niklas

El amor como pasión. La codificación de la intimidad, Barcelona, Península, 1985.

Martínez, J. R.

"Introducción del fonógrafo en San Luis Potosí", en Cuadernos Potosinos de Cultura Científica del Museo Casa de la Ciencia y el Juego, 1:1 (2008), pp. 1-18.

McGowan, Gerald L. (coord.)

La Revolución Mexicana a través de sus documentos, México, Universidad Nacional Autónoma de México, 1987, t. III.

McLuhan, Marshall

Comprender los medios de comunicación. Las extensiones del ser humano, Barcelona, Paidós, 2009.

Milhe Bruno, Guadalupe

Una visión de 1890 hacia el futuro: el correo y Tomás A. Edison, México, Miguel Ángel Porrúa, 1991.

Pineda Gómez, Francisco

La revolución del sur, México, Era, 2005. 
REED, John

México insurgente, Tafalla, Txalaparta, 2005.

Sunkel, Guillermo

El consumo cultural en América Latina: construcción teórica y líneas de investigación, Bogotá, Convenio Andrés Bello, 2006.

Tannenbaum, Frank

“Technology and Race in Mexico”, en Political Science Quarterly, 61: 3 (sep. 1946), pp. 365-383.

Thompson, Emily

"Machines, Music, and the Quest for Fidelity: Marketing the Edison Phongraph in America. 1877-1925”, en The Music Quaterrly, 79: 1 (primavera 1995), pp. 131-171.

Villa Rojas, Alfonso

“Los mayas del actual territorio de Quintana Roo”, en Estudios etnológicos. Los mayas, México, Universidad Nacional Autónoma de México, 1995.

WOMACK, John

Zapata y la Revolución Mexicana, México, Siglo Veintiuno editores, 2014. 